\title{
Water Quality Monitoring Systems based on Intelligent Agents: A Systematic Literature Review
}

\author{
Adrian Vázquez Osorio ${ }^{1}$, Carlos Armando Soto Barrera ${ }^{2}$, Juan Pablo Soto ${ }^{1}$ \\ Elvira Rolón Aguilar ${ }^{3}$, Julio César Rolón Aguilar ${ }^{3}$ \\ ${ }^{1}$ Universidad de Sonora, Mexico \\ \{adrian.vazquez, juanpablo.soto\}@unison.mx \\ ${ }^{2}$ Universidad Tecnológica de Guaymas, Mexico \\ csoto@utguaymas.edu.mx \\ ${ }^{3}$ Universidad Autónoma de Tamaulipas, Mexico \\ \{erolon, jrolon\}@docentes.uat.edu.mx
}

\begin{abstract}
Water is a vital resource for life; however, although most of the planet is covered with water, only a small percentage corresponds to fresh water. Also, a low percentage of fresh water corresponds to drinking water, that is, water useful for human consumption. Despite this, the society has been contaminating the sources of fresh water, reducing more and more the amount of water available for human use. This paper presents a systematic literature review on the various modern mechanisms to monitor water quality, through the use of technology to take measurements and the use of storage devices. A comparison is made between studies regarding in this topic and a set of stands of work is proposed to be developed in the future. This review may guide the reader about the basis of available of information and communication technologies and their application in management systems to monitor water quality, in order to facilitate the search for planning and design of sustainable new system.
\end{abstract}

Keywords: water quality monitoring, multiagent system, intelligent agent.

\section{Introduction}

Water is a vital resource for human health. Although around $71 \%$ of the world is covered with water, only $2.5 \%$ corresponds to fresh water. In developing countries, $80 \%$ of the population has no access to fresh water [1]. Water is widely used for industry, for domestic uses and agricultural activities, etc. Furthermore, water requires a fulfillment of a variety of characteristics that include the water quality standard. To ensure that the water quality complies with the required characteristics it is necessary to have systems that monitor the corresponding parameters and validate that they are within the acceptable ranges.

Intelligent agents represent one of the promising technology for building complex software systems [2], due to the simplicity of representing complex systems; particularly, they are useful among systems which require constant monitoring and decision making. Moreover, wireless sensor networks come to offer great support to intelligent agents, specifically in regards to water quality. 
The remainder of the paper is organized as follows: In section two, background related with water quality monitoring is described along with how multiagent systems have occurrence in the software systems developed for this aim. In section three, the methodology used to obtain the corresponding systematic literature review to water quality monitoring is described. Later, section four, the results obtained from the literature review, presenting the important characteristics from this topic are shown. Finally, conclusions and future work are outlined in section five.

\section{Background}

For many years, the environment has suffered a devastating impact resulting from human activity increase. In developing countries, particularly, the activities from mining companies contribute to a negative impact in the environment [1].

In order to mitigate environmental problems, Environmental Monitoring Systems (EMS) have been developed in various areas. Currently, there are EMS for air and water quality, animal tracking, and monitoring systems for earthquakes, among others.

Particularly, in this work, it is consider that the systems for Water Quality Monitoring (WQM) are paramount due to different factors that affect water, such as (1) each living creature needs water to live, (2) only $2.5 \%$ of the accessible water is fresh water, and (3) approximately $20 \%$ of the world population has no access to fresh water.

Currently, water is contaminated from different sources, including the ones brought by the modernity of big cities. The quality of the water describes the composition of the water regarding its chemical, physical and biological properties; thus, it requires constant monitoring and, in case of biological or chemical contamination, making decisions in real time to mitigate the consequences.

WQM can be described as a method to sample and analyze water conditions and characteristics regularly [1]. Usually, it involves monitoring fresh water sources, such as rivers, lakes, springs, groundwater, wells, etc., to ensure that the water source provides reliable water supplies for its consumption and daily activities. The World Health Organization (WHO) has determined parameters that specify the allowed quantities of certain chemicals that can be found in water, for instance magnesium, manganese, calcium, and sodium, among others.

The development of WQWs is currently directed to the field of Intelligent Agents, for Intelligent Agents represent technology to create complex software systems. Having this in mind, Multi Agent Systems (MAS) are created. These are comprised of at least two Intelligent Agents that can interact among each other.

There are two approaches in the development of WQM systems based on agents. The first line consists of the administration of information using distributed databases and technology targeted to objects; the objective is to use software agents for the efficient processing of the information distributed. The second line is the development of software capable to predict events and emit warnings to mitigate disasters; these systems use artificial intelligence techniques (neural networks, data mining, etc.) for identifying environmental incidents beforehand [2].

MAS represent the best solution for WQM systems, since the appliances are modular (water distribution systems are built my modules), decentralized (can be broken down into autonomous stations geographically distributed), adaptable (the system structure 
can change as new entities are added or old entities are replaced), and complex (entities show various behaviors that can interact sophistically; as well as the number of entities is considerable).

In general, these systems are tough (a point of failure can be prevented), efficient (less complex calculations if the control is distributed), flexible (the communication language of the agent allows complex interactions), open (due to the use of the FIPA standard, the agent can be designed by different developers), and scalable (it is easy to add new agents to a MAS) [2].

In this work, it is intended to obtain relevant information about Water Quality Monitoring systems, particularly in rivers, so it can be suitable to be used in the water pollution case of the Sonora river.

\section{Methodology}

This process is based on the methodology proposed by Kitchenham [3]. The objective of this work is the systematic literature review focused on the Water Quality Monitoring Systems and Multiagent Systems topics. The methodology consists of various steps, which are described in the following sub-sections.

\subsection{Research Questions}

Research questions are the guide to identify bibliographic references that allow us to clarify where the research proposed suits best. The questions considered for this work are the following:

Question 1. Which are the essential factors to measure water quality?

Question 2. Do software architectures based on multiagent systems to monitor water quality from rivers exist?

Regarding question 1 , it is important to know the measurable elements to ensure water quality; particularly, to know if water is suitable for human consumption or if it can be used to water plants.

Question 2 is the central part of this work, knowing if there are technological tools that allow monitoring water quality in real time in rivers mainly although other sources such as lakes, lagoons, etc., could be considered.

\subsection{Search Process}

To obtain the terms to be searched, the questions made were analyzed, reaching to the following research topics:

(1) Water Quality Monitoring,

(2) Water Pollution Monitoring,

(3) Software Agent,

(4) Multi-agent System.

The structure of the query made is based on these topics, connecting with the OR conjunction the topics from the same area and with the AND conjunction the topics 
from different areas; in essence, the query ends in the following manner: "(1 OR 2) AND (3 OR 4 OR 5)".

For the search, different sites that deal with information of research topics were found. For this work, only English or Spanish written articles that were available were considered. Table 1 shows the list of information sources (analyzed from [4] and [5] to do the search.

Table 1. Digital databases sources.

\begin{tabular}{|l|l|}
\hline Name & Link \\
\hline ACM Digital Libray & https://dl.acm.org \\
\hline AIS eLibrary & http://aisel.aisnet.org \\
\hline Elsevier Science Direct & https://onlinelibrary.wiley.com \\
\hline Google Scholar & https://scholar.google.com \\
\hline IEEE Xplore & https://ieeexplore.ieee.org \\
\hline Scopus & https://www.scopus.com \\
\hline SpringerLink & https://link.springer.com \\
\hline
\end{tabular}

To conduct the corresponding research, each database has its corresponding search pattern; in spite of being similar patterns, some show slight structure changes. For this work, the following search requests in each of the sources mentioned before were conducted.

\section{- ACM Digital Libray}

(+water +quality +monitoring +water + pollution +monitoring multi-agent system "multi agent" software agent)

- AIS eLibrary

(water quality monitoring or water pollution monitoring) and

(software agent or multi-agent system or multiagent system)

- Elsevier Science Direct

("water quality monitoring" OR "water pollution monitoring") AND

("multiagent system" OR "multi-agent system" OR "software agent")

- Google Scholar

"water quality" "monitoring" "water pollution"

"multi agent system" "multi-agent system" "software agent"

\section{- IEEE Xplore}

( (water and quality and monitoring) or (water and pollution and monitoring) ) and ( (software and agent) or (multiagent and system) or (multi-agent and system) )

\section{- Scopus}

("water quality monitoring" OR "water pollution monitoring") AND

("multiagent system" OR "multi-agent system" OR "software agent") 


\section{- SpringerLink}

("water quality monitoring" or "water pollution monitoring") and

("software agent" or "multi-agent" or "multiagent system")

\subsection{Inclusion Criteria}

The inclusion/exclusion criterion used to select the most relevant studies was applied on the title and summary of each document. Nonetheless, in some cases it was necessary to revise the complete text from the document to confirm that it was relevant. During the selection of papers, it was considered that some results appear in more than one source, and repeated studies were identified.

After inquiring the data sources, a total of 25 documents were retrieved, from which 22 turned out to not be repeated. Once that the inclusion/exclusion criterion was applied to each of them, only 8 were considered relevant for the questions that this literature review tries to answer. Table 2 shows the total number of results and primary studies obtained from each source.

Table 2. Documents obtained from the query.

\begin{tabular}{|l|c|c|c|}
\hline Source & Totals & Not repeated & Primary \\
\hline ACM Digital Libray & 2 & 2 & 2 \\
\hline AIS eLibrary & 2 & 2 & 0 \\
\hline Elsevier Science Direct & 6 & 6 & 2 \\
\hline Google Scholar & 3 & 3 & 2 \\
\hline IEEE Xplore & 2 & 2 & 1 \\
\hline Scopus & 3 & 1 & 0 \\
\hline SpringerLink & 7 & 6 & 1 \\
\hline Total & 25 & 22 & 8 \\
\hline
\end{tabular}

\subsection{Information Extraction}

The extraction is the relevant information to the research topic that has been obtained from the primary studies considered on Table 2. A brief overview of each of the selected documents is presented below.

Doc 1. Applying Agent Technology in Water Pollution Monitoring Systems (2006) [2]. The authors focus on a water pollution monitoring application based on intelligent agents. This work was developed in Rumania to satisfy the European Legislation. The system consists of various stations (each represented by an agent) that monitor water quality, and when the measurement of certain parameters shows excess, warnings are sent to a supervisor (supervisor agent). This work is the design of a prototype for future implementation.

Doc. 2. An agent-based model for water quality control (2007) [6]. The authors present the architecture developed for a Water Quality Monitoring system, which consists of the depiction of three monitoring stations: one supervision station and two regular stations; each station is controlled by intelligent agents and measuring devices. Moreover, they demonstrate an example of a developed application. Lastly, the authors propose a model based on agents with the ability to make decisions in real time, considering this as a first step to the development of this type of systems. 
Doc. 3. On the Distributed Water Pollution Control Solving with an Agent-Based Approach (2008) [7]. The authors rely on a Water Quality Monitoring system, based on intelligent agents to show the troubleshooting of a geographically distributed problem. The authors determined the principal parameters required to measure water quality; they show an architecture of the monitoring system in which the functionality of intelligent agents is shown. This work emphasizes the need to develop a predictive system that provides warnings when there is a situation of imminent danger.

Doc. 4. Agents as a Decision Support Tool in Environmental Processes: The State of the Art (2009) [8]. The authors focus on environmental problems and how much they affect current society, such as water pollution (including oceans, rivers, lakes, etc.), air pollution and soil pollution. Moreover, they provide a list of developed systems to solve some of these problems; these systems are categorized in one of three categories: environmental information administration, environmental decision-making support systems and environmental simulation systems. In any moment, they show intelligent agents as the best option for the development of these complex systems.

Doc. 5. A Wireless Sensor Network Based Water Monitoring System (2012) [9]. The authors propose a platform to monitor water quality, in which they use Wireless Sensor Networks (WSN) and Radio Frequency Identification systems (RFID). The platform consists of a group of mobile sensors with RFID readers, which are introduced into the aquatic entity (river, lake, ocean, etc.) to be gathered after; these sensors move with the water flow while they do quality measurements; a group of RFID cards are placed on the edges of the aquatic entity to reference the location of the mobile sensors. The authors argue that cost, energy and performance advantages, among other factors, are obtained with this platform. Even though they do not provide a prototype, results of a conducted simulation are shown.

Doc. 6. Multi-Agent Based Simulation of Environmental Pollution Issues: A Review (2014) [10]. The authors provide a literature review of conducted studies on modeling and simulation of environmental settings, all of them based on the approach of intelligent agents and emphasizing on the three components of an environmental problem: social, economic and ecological. Some of the presented systems are the air quality, the species evolution (corals, sea turtles, forests, etc.), the behavior of societies in cities, agriculture, water pollution, among others.

Doc. 7. An Ontology-based Knowledge Modelling Approach for River Water Quality Monitoring and Assessment (2016) [11]. The authors present an ontology of the modeling to evaluate water quality in a river, depict the data of water quality and make the semantic relevance between the concepts involved. The presented framework consists of the data acquisition layer, communication \& management layer and data assessment layer. This system is validated in 5 water samples.

Doc. 8. Water quality monitoring using wireless sensor networks: Current trends and future research directions (2017) [1]. The authors show a revision of works developed in Water Quality Monitoring from traditional methods to the most advanced technological methods. Traditional methods are going to the water source, taking samples from it and transporting them to a laboratory to be analyzed; while advanced methods use Wireless Sensor Networks (they show a list of the market sensors), which can detect different parameters (show in a table) of the water quality in situ. Finally, the authors present a range of possible future development works. 
After revising the information of each work made, they have been classified in two rubrics: (a) anthologies' works, and (b) applications' works. Anthologies' works correspond to documents 4 and 6. In these works an analysis on developed works in a given topic is made. In Table 3, a list of developed systems relevant for this work is shown. In spite of the fact that the authors present various systems, there are very few who focus on water monitoring.

Table 3. Developed applications.

\begin{tabular}{llll}
\hline System & Description & Agents & Status \\
\hline Control-MWS & $\begin{array}{l}\text { Water pollution monitoring system } \\
\text { from a town water system. }\end{array}$ & $\begin{array}{l}\text { Pump station, } \\
\text { tank. }\end{array}$ & Implemented \\
\hline WPMS & Water pollution monitoring for the & $\begin{array}{l}\text { Monitor, } \\
\text { supervisor y } \\
\text { cogulatory compliance. }\end{array}$ & Modelled \\
& & & \\
& & & \\
\hline
\end{tabular}

Table 4. Developed architectures comparison.

\begin{tabular}{|c|c|c|c|}
\hline Source & Technology & Architecture & Parameters \\
\hline $\begin{array}{l}\text { Doc. } 1 \\
\text { (Oprea, } \\
\text { Nichita) } \\
\text { (Rumania) }\end{array}$ & $\begin{array}{l}\text { Automatic } \\
\text { analyzers. } \\
\text { Multiagent } \\
\text { Systems, GAIA } \\
\text { methodology. }\end{array}$ & $\begin{array}{l}\text { Based on entities: Agents } \\
\text { (Monitor, Supervisor and Control), } \\
\text { Measurement Devices and Human } \\
\text { Operator. }\end{array}$ & $\begin{array}{l}\text { Temperature, } \\
\text { turbidity, } \\
\text { conductivity, } \\
\text { chlorine. }\end{array}$ \\
\hline $\begin{array}{l}\text { Doc. } 2 \\
\text { (Nichita, } \\
\text { Oprea) } \\
\text { (Rumania) }\end{array}$ & $\begin{array}{l}\text { Sensor Networks, } \\
\text { Spectrometers } \\
\text { UV-VIS } \\
\text { TROPOS } \\
\text { methodology, } \\
\text { UML, FIPA, } \\
\text { JADE agent }\end{array}$ & $\begin{array}{l}\text { Interaction among agents. } \\
\text { Three monitoring stations model: } 1 \\
\text { supervision station, } 2 \text { regular } \\
\text { stations. Each station includes: } \\
\text { Supervision Agent, Pollution } \\
\text { Control Device, Database } \\
\text { Management Agent, and } \\
\text { Reasoning Agent. }\end{array}$ & $\begin{array}{l}\text { Turbidity, organic } \\
\text { carbon, nitrate, } \\
\text { benzene, ammonium } \\
\text { (NH4), dissolved } \\
\text { oxygen (DO), PH, } \\
\text { oxidation-reduction } \\
\text { potential (ORP), } \\
\text { redox, electrical } \\
\text { conductivity, } \\
\text { temperature. }\end{array}$ \\
\hline $\begin{array}{l}\text { Doc. } 3 \\
\text { (Oprea, } \\
\text { Nichita) } \\
\text { (Rumania) }\end{array}$ & $\begin{array}{l}\text { GAIA } \\
\text { methodology, } \\
\text { UML Agent }\end{array}$ & $\begin{array}{l}\text { Interaction among agents. } \\
\text { Three monitoring stations model: } 1 \\
\text { supervision station, } 2 \text { regular } \\
\text { stations. Each station includes: } \\
\text { Supervision Agent, Pollution } \\
\text { Control Device, Database } \\
\text { Management Agent, and } \\
\text { Reasoning Agent. }\end{array}$ & $\begin{array}{l}\text { Rain occurrences, } \\
\text { flow, color, PH, } \\
\text { solids, conductivity, } \\
\text { turbidity, particles' } \\
\text { size analysis, residual } \\
\text { disinfectant, organic } \\
\text { matter, ammonium. }\end{array}$ \\
\hline $\begin{array}{l}\text { Doc. } 5 \\
\text { (Rekhis, } \\
\text { Ellouze, } \\
\text { Boudriga) } \\
\text { (Túnez) }\end{array}$ & $\begin{array}{l}\text { Wireless Sensor } \\
\text { Networks (WSN), } \\
\text { Radio Frequency } \\
\text { Identification } \\
\text { systems (RFID) } \\
\end{array}$ & $\begin{array}{l}\text { Sensors with RFID readers } \\
\text { interacting with RFID cards } \\
\text { located in a stationary position. }\end{array}$ & $\begin{array}{l}\text { PH, temperature, } \\
\text { dissolved oxygen, } \\
\text { turbidity. }\end{array}$ \\
\hline $\begin{array}{l}\text { Doc. } 7 \\
\text { (Ghazi, } \\
\text { Khadir, } \\
\text { Dugdale) } \\
\text { (China) }\end{array}$ & $\begin{array}{lr}\text { Wireless } & \text { Sensor } \\
\text { Networks } & \text { (WSN), } \\
\text { Protégé, } & \text { OWL } \\
\text { syntax, } & \text { Jena, } \\
\text { Sparql } & \end{array}$ & $\begin{array}{l}\text { The monitoring system consists of } \\
3 \text { layers: data acquisition, } \\
\text { communication and } \\
\text { administration, and data } \\
\text { asessment. }\end{array}$ & $\begin{array}{l}\text { PH, temperature, } \\
\text { conductivity, } \\
\text { fluoride, lead, } \\
\text { chromium, cadmium, } \\
\text { copper. }\end{array}$ \\
\hline
\end{tabular}


The application works were analyzed to obtain relevant information from each of them. In Table 4 the characteristics considered mainly important in the revised documents are shown.

Additionally, it is interesting to have a classification according to the country in which the work has been developed. This is presented in Figure 1; the graphic shows the country, the quantity of documents and the percentage of each quantity.

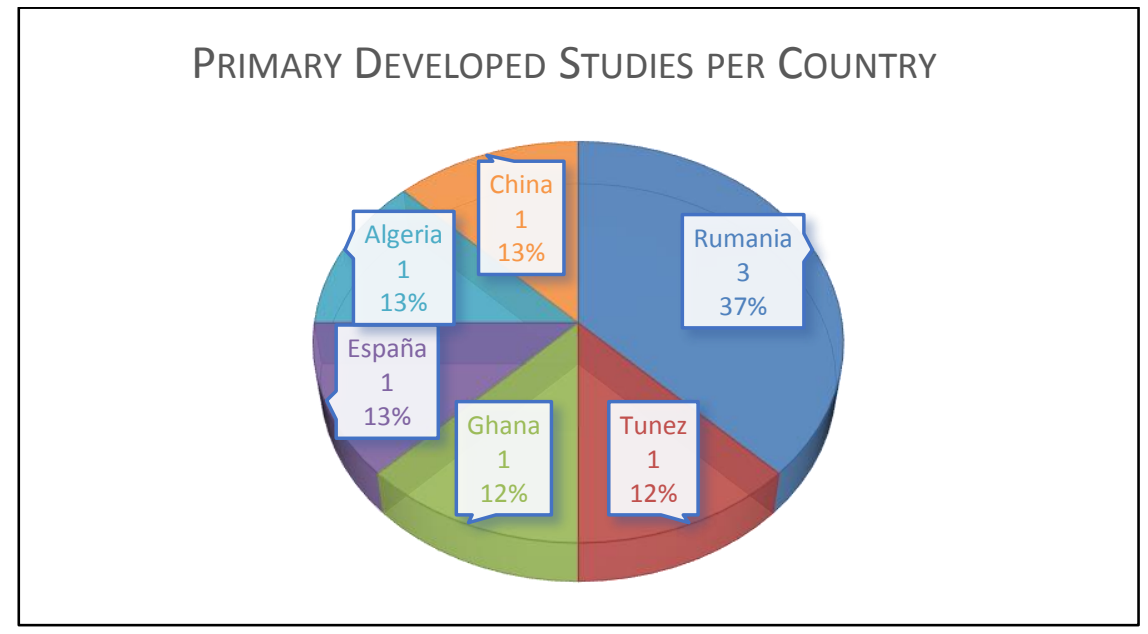

Fig. 1. Primary developed studies per country.

In Figure 2, the geographic location of the selected documents is shown, which are mainly from countries in the European and African continents.

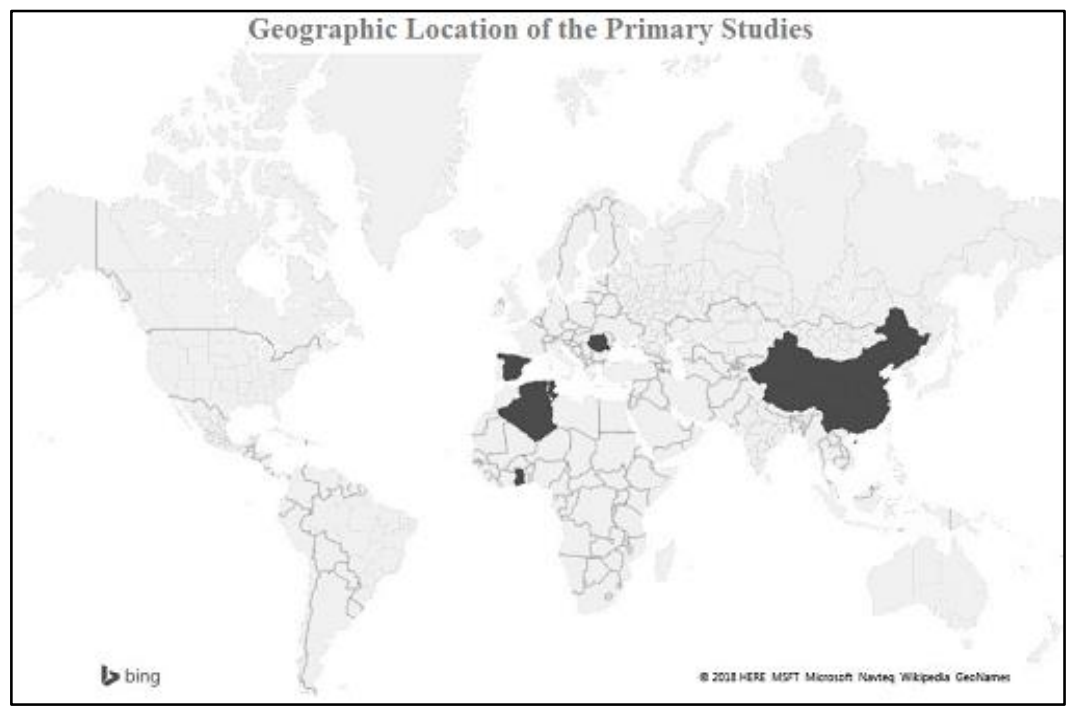

Fig. 2. Geographic location of the primary selected studies. 


\section{$4 \quad$ Results}

Among the important aspects to analyze from the systematic literature review made, what stands out are the quantity of the documents found, the developed systems, the geographic location of the developed works, as well as the authors of each work.

Firstly, it can be seen that the total number of results ( 25 documents) is small in comparison to the results obtained in systematic literature reviews done in other areas of interest, even more if it is considered the reduced number of primary studies (8) identified. However, this number is not a negative result for the systematic literature review, since it can state that a need for greater development on this area exists. It can be considered an evidence that the current available research in this topic is small and that there is further work to do. As a side note, it is important to mention that the research for the topics of water and intelligent agents was made independently, obtaining quantities larger than 70,000 and 60,000 documents, respectively.

Secondly, it can be mentioned that a great amount of environmental monitoring system exists, according to what is stated in [8] and [10]. Nonetheless, there are few systems focused on water pollution (in comparison to the systems focused on air pollution). Furthermore, the majority of the developed works are in modelling and/or simulation stages. It is also important to mention that the works are based on the stablished regulations made by the country they are developed in; nonetheless, international regulations exist and can be applied to them. Moreover, the works run their own measurement parameters, coinciding in some of them, but varying according to the measurement devices used in each presented system.

Thirdly, it can be seen that the greater quantity of development is found in Europe and Africa, which is not surprising, since according to the United Nations (UN), Africa is the continent that suffers the most problems of pollution and fresh water distribution. Something important to consider is that Oprea and Nichita are the researchers who possess the biggest amount of works related to this topic.

Finally, it can be observed that the works made are relatively recent, the oldest being from year 2006 and the most recent from the year 2017. This leads to think about the topic of monitoring water and how it is gaining importance in the last years. It is important to indicate that the first documents described ([2], [6] y [7]) correspond to the same authors; with this, there is probably a reference to the same monitoring system developed.

\section{Conclusion}

This work presents a systematic literature review of the water quality monitoring systems papers that gather and analyze the most important current research made regarding this topic, attaining to find new research activities. Based on this study, it can be confirmed that the monitoring systems are a recent topic which has several development options, water quality being one of the primary environmental problems along with air pollution, soil pollution, among others.

As a result of the systematic literature review, several topics related to monitoring systems have been discussed; however, the majority only presents a simulation instead 
of field applications. Apart from that, the importance and utility that intelligent agents have in the design of these systems is enhanced.

In the revision of this work, different measurement parameters for water quality were obtained, as well as references for the technology that can measure those parameters.

Determining the correct distribution of wireless sensors, energy administration of the sensors, and the generic modeling of the structures of the rivers are recurrent problems mentioned in the research papers revised.

Acknowledgements. This work is partially supported by CONACYT through the call 291236 and by the University of Sonora through the agreement R/494/2017.

\section{References}

1. Sarpong Adu-manu, K., Tapparello, C., Heinzelman, W., Apietu Katsriku, F., Abdulai, J.: Water Quality Monitoring Using Wireless Sensor Networks: Current Trends and Future Research Directions. ACM Trans. Sens. Networks (2017)

2. Oprea, M., Nichita, C.: Applying Agent Technology in Water Pollution Monitoring Systems. In: 2006 Eighth International Symposium on Symbolic and Numeric Algorithms for Scientific Computing, pp. 233-238 (2006)

3. Kitchenham, B., Pearl Brereton, O., Budgen, D., Turner, M., Bailey, J., Linkman, S.: Systematic literature reviews in software engineering - A systematic literature review Information and Software Technology (2009)

4. Hossain, E., Babar, M.A., Paik, H.: Using Scrum in Global Software Development: A Systematic Literature Review. In: 2009 Fourth IEEE International Conference on Global Software Engineering (2009)

5. Monasor, M.J., Vizcaino, A., Piattin, M., ,: Docencia en Desarrollo Global de Software: Una Revisión Sistemática. In: Jornadas de Enseñanza Universitaria de la Informática (JENUI), pp. 221-228 (2011)

6. Nichita, C., Oprea, M.: An agent-based model for water quality control. Comput. Aided Chem. Eng. 24 (2007)

7. Oprea, M., Nichita, C.: On the distributed water pollution control solving with an agentbased approach. In: Studies in Computational Intelligence (2008)

8. Aulinas, M., Turon, C., Sanchez-Marr, M.: Agents as a Decision Support Tool in Environmental Processes: The State of the Art. In: Advanced Agent-Based Environmental Management Systems (2009)

9. Rekhis, S., Ellouze, N., Boudriga, N.: A wireless sensor network based water monitoring system. In: Proceedings of the $8 \mathrm{~h}$ ACM symposium on QoS and security for wireless and mobile networks - Q2SWinet'12 (2012)

10. Ghazi, S., Khadir, T., Dugdale, J.: Multi-Agent Based Simulation of Environmental Pollution Issues: A Review. In: Corchado J.M. et al. (eds) Highlights of Practical Applications of Heterogeneous Multi-Agent Systems. The PAAMS Collection. PAAMS 2014. Communications in Computer and Information Science, vol 430. Springer, Cham (2014)

11. Xiaomin, Z., Jianjun, Y., Xiaoci, H., Shaoli, C.: An Ontology-based Knowledge Modelling Approach for River Water Quality Monitoring and Assessment. In: Procedia Computer Science (2016) 